\title{
Research
}

Hannah V Thornton, Peter S Blair, Andrew M Lovering, Peter Muir and Alastair D Hay

\section{Clinical presentation and microbiological diagnosis in paediatric respiratory tract infection:}

\author{
a systematic review
}

\begin{abstract}
\section{Background}

Antibiotic prescribing decisions for respiratory tract infection (RTI) in primary care could be improved if clinicians could target bacterial infections. However, there are currently no evidence-based diagnostic rules to identify microbial aetiology in children presenting with acute RTIs.
\end{abstract}

\section{Aim}

To analyse evidence of associations between clinical symptoms or signs and detection of microbes from the upper respiratory tract (URT) of children with acute cough.

\section{Design and setting}

Systematic review and meta-analysis.

\section{Method}

A literature search identified articles reporting relationships between individual symptoms and/or signs, and microbes detected from URT samples. Associations between pathogens and symptoms or signs were summarised, and meta-analysis conducted where possible.

\section{Results}

There were 9984 articles identified, of which 28 met inclusion criteria. Studies identified 30 symptoms and 41 signs for 23 microbes, yielding 1704 potential associations, of which only 226 $(13 \%)$ have presently been investigated. Of these relevant statistical analyses were presented for 175 associations, of which $25 \%$ were significant. Meta-analysis demonstrated significant relationships between respiratory syncytial virus (RSV) detection and chest retractions (pooled odds ratio [OR] 1.9, 95\% confidence interval $[\mathrm{Cl}]=1.6$ to 2.3), wheeze (pooled OR 1.7, $95 \% \mathrm{Cl}=1.5$ to 2.0 ), and crepitations/crackles (pooled OR $1.7,95 \% \mathrm{Cl}=1.3$ to 2.2 ).

\section{Conclusions}

There was an absence of evidence for URT pathogens other than RSV. The meta-analysis identified clinical signs associated with RSV detection, suggesting clinical presentation may offer some, albeit poor, diagnostic value. Further research is urgently needed to establish the value of symptoms and signs in determining microbiological aetiology and improve targeting of antibiotics in primary care.

\section{Keywords}

child; diagnosis; microbiology; point-of-care systems; primary health care; respiratory tract infections.

\section{INTRODUCTION}

Respiratory tract infection (RTI) is one of the most common reasons why children present to primary care. A recent review by the UK's National Institute for Health and Care Excellence (NICE) concluded that antibiotics do not confer a clinically significant reduction in the time needed to recover from an RTI, and recommended that antibiotics are not prescribed for RTI in children who are otherwise healthy. However, despite this, prescribing rates remain high ${ }^{2}$ and are increasing ${ }^{3}$ in UK general practice. This results in the treatment of children who experience no clinical benefit, yet are exposed to the potential adverse effect of antibiotics. This practice increases the potential for development of antimicrobial resistance.

No diagnostic or prognostic rule has been developed to distinguish bacterial from viral RTI that would be expected to respond to antibiotics. In the absence of this information, a diagnostic gap exists between the presentation of RTI and the appropriate management. This leads to diagnostic uncertainty, which is reflected in a wide variation in antibiotic prescribing rates between clinicians, ${ }^{5}$ practices, ${ }^{6}$ and countries.?

The aim of this review was to identify the extent of evidence-reporting

HV Thornton, BM, PhD, research assistant; PS Blair, $\mathrm{PhD}$, reader in medical statistics: AD Hay, MD, MRCP, FRCGP, DCH, professor of primary care and NIHR research professor Centre for Academic Primary Care, School of Social and Community Medicine, NIHR School of Primary Care Research, University of Bristol, Bristol. AM Lovering. PhD, professor of primary care and NIHR research professor, Bristol

Centre for Antimicrobial Research and Evaluation (BCARE), North Bristol NHS Trust, Southmead Hospital, Bristol, Bristol. P Muir, PhD, consultant clinical scientist, Specialist Virology Centre, Public Health Laboratory Bristol, Public Health England, Bristol, Bristol. associations between clinical presentation and the detection of microbes in the upper respiratory tract (URT) in children presenting to healthcare services with RTIs associated with acute cough - cough being the most common presenting symptom of $\left.\mathrm{RT}\right|^{8}$ - and to conduct meta-analysis where appropriate.

\section{METHOD}

\section{Search strategy}

The search strategy was designed to identify observational studies and reviews that reported the relationships between clinical presentation and microbes sampled from the URT in children presenting with cough. Included studies were required to present data at the level of individual patients, and could be conducted in any country and published in any language. MEDLINE, Embase, and the Cochrane database using the OVID platform were searched on 30 November 2012, and the search was updated on 12 April 2014.

The MEDLINE search strategy is presented in Appendix 1 and used combinations of MeSH terms and text words for clinical symptoms and signs, disease causation, microbes, and clinical diagnoses. The search strategy was adapted for use in both MEDLINE and Embase. The search was not limited to the English language,

\section{Address for correspondence}

Hannah Thornton, Centre for Academic Primary Care, NIHR School for Primary Care Research, School of Social and Community Medicine, University of Bristol, Canynge Hall, 39 Whatley Road, Bristol, BS8 2PS, UK.

E-mail: hannah.thorntondabristol.ac.uk Submitted: 10 March 2014; Editor's response: 10 April 2014; final acceptance: 9 June 2014. CBritish Journal of General Practice

This is the full-length article (published online 26 Jan 2015) of an abridged version published in print. Cite this article as: $\mathbf{B r} \mathbf{J}$ Gen Pract 2015; DOI: 10.3399/bjgp15X683497 


\section{How this fits in}

No diagnostic test is routinely available to help clinicians distinguish bacterial from viral respiratory tract infections (RTIs) in children in primary care. Using symptoms and signs to identify the microbiological aetiology of RTI could improve appropriate use of antibiotics. This systematic review reports an absence of evidence for the relationship between clinical symptoms or signs and upper respiratory tract pathogens in children with RTI. Only 13\% of the potential relationships between clinical characteristics and microbiology have been investigated, with 25\% of these reporting significant associations, most notably for respiratory syncytial virus. Further research is urgently needed to establish the value of symptoms and signs for making a microbiological diagnosis and improve the targeting of antibiotic treatment to children.

no time restrictions were applied, and translations were obtained where required. Reference lists of all full-text articles were also screened.

\section{Study selection}

Studies eligible for inclusion were all peerreviewed, quantitative studies reporting microbiological and clinical data from children presenting to a healthcare service or research team with a diagnosis or symptoms of an RTI associated with cough. Studies recruiting from primary care, secondary care, and community settings were included. Studies were excluded if data presented were selected based on a subgroup of children with positive microbiology results, or if children were

\section{Box 1. Inclusion and exclusion criteria for this systematic review}

Inclusion criteria

1. Published peer-reviewed, quantitative studies reporting microbiological outcome.

2 Participants present to a healthcare service or research team with a diagnosis, or symptoms, of an RTI that includes (or is very likely to include) a cough.

3. Studies report either:

a. The strength of associations between specific symptoms and/or signs and pathogens identified from respiratory tract samples; or

b. Raw data cross-tabulating the incidence of specific symptoms and/or signs against pathogens identified from respiratory tract samples.

4. Studies report data from children; studies that recruit both adult and child participants must report child data separately from adult data.

\section{Exclusion criteria}

1. Studies where children are selected for entry into the study on the basis of positive microbiology results.

2. Studies where data is not presented from the whole cohort, but from a subgroup selected on the basis of microbiology results.

3. Microbiology results from pulmonary, blood, urine, or faecal samples.

4. Study participants recruited from intensive care.

5. Study participants recruited from a population of children with a high prevalence of pre-existing chronic disease or immune incompetence. recruited from intensive care or from a population with a high prevalence of pre-existing chronic disease or immune incompetence. Full inclusion and exclusion criteria are listed in Box 1.

Titles and abstracts of all articles identified were reviewed by one author, and those that were not relevant were excluded. Twenty per cent of abstracts were independently reviewed by one of two other authors, with good agreement ( $\kappa$ 0.89). Full-text copies of all included articles were independently reviewed by three authors, and any eligibility disagreements resolved by discussion.

\section{Data extraction and quality assessment}

Data were extracted from studies included in the review using a purpose-designed Access form and Excel spreadsheet. Descriptive variables extracted were participant age, study setting, design, country of recruitment, URT sample site, laboratory methods, microbes identified, analysis methods, whether children with prior antibiotic use were included in the study, and whether study inclusion criteria specified any named RTIs. Outcome data extracted were any symptoms and signs reported that were related to the clinical presentation of RTI. Quality assessment was conducted for all included articles using a purpose-designed form containing criteria based on recommendations from the GRADE guidelines and QUADAS-2 checklist. 9.10

\section{Data synthesis and analysis}

Visual representation of the number of relationships sought was achieved by crosstabulation of reported symptoms and signs against the respiratory pathogens identified. Where three or more studies reported raw data for an association between a pathogen and a symptom or sign, data were extracted, results checked for homogeneity, and metaanalysis carried out.

Statistical analysis was completed in STATA (version 12). Pooled odds ratios (OR) were obtained by fixed-effects metaanalysis to investigate the odds of pathogen detection in the presence of individual symptoms and signs. Heterogeneity was assessed using the 12 statistic, and the possibility of publication bias was assessed using funnel plots.

\section{RESULTS}

\section{Study characteristics}

Searches identified 9984 articles of which 2502 were duplicates and 6378 excluded on the basis of title. There were 1104 abstracts screened and the full texts of 216 articles 
Figure 1. Flow chart showing inclusion and exclusion stages for articles in the review.

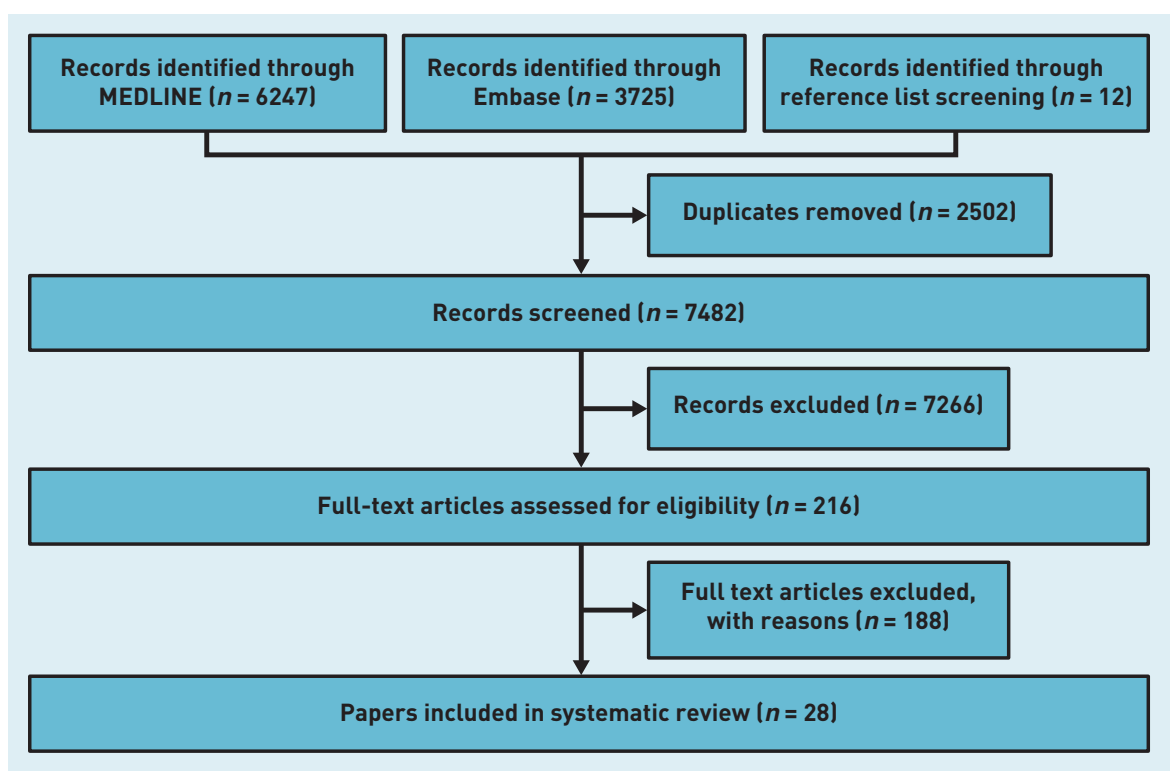

were read. Twenty-eight articles were eligible for inclusion in the review (Figure 1).

Raw data were presented by three or more studies for the associations between six individual clinical signs and pathogen detection, and this data, extracted from 10 studies, were included in the meta-analysis.

Study characteristics are summarised in Table 1. Half of studies 14 out of 28 $50 \%$ of totall recruited only infants aged $0-1$ years, 1 out of 28 (4\%) recruited only children aged from 2-17 years, and 3 out of $28(11 \%)$ recruited infants and children aged from 0-17 years. All studies used samples taken from the nasopharynx, with the majority (18 out of $28,64 \%$ ) using nasopharyngeal aspirates. Laboratory methods of pathogen identification varied within and between studies, and included polymerase chain reaction (PCR) lused in 18 out of 28 studies, $65 \%$ ), bacterial culture ( 4 out of 28 studies, 14\%), assays (real-time analyte specific reagent or enzyme-linked immunoassay) ( 4 out of 28, 14\%), and direct immunofluorescence ( 5 out of $28,18 \%$ ). The majority of studies (20 out of $28,71 \%$ ) were set in high-income countries. ${ }^{11}$

Quality assessments are summarised in Appendix 2. Studies were found to be of generally good quality and no study was excluded from this review on the basis of poor quality.

\section{Symptoms, signs, and microbes investigated in the literature}

Data were sought for 24 individual pathogens and were identified for 71 symptoms and signs, yielding 1704 potential comparisons (Appendix 3). Of the potential comparisons 226 (13\%) were investigated by one or more study, within which 19\% showed statistically significant associations; $58 \%$ showed no significant association; and 23\% presented no relevant statistical analysis (Figure 2).

\section{Signs associated with RSV detection}

Six associations were identified that were examined by three or more studies presenting raw data. All six associations described the relationships between respiratory syncytial virus (RSV) and clinical signs. Raw data were extracted, and metaanalysis found significant associations between RSV detection and chest retractions IOR $1.9,95 \% \mathrm{Cl}=1.6$ to $2.2, I^{2}=48 \%, P$-value for 12 statistic 0.074), wheeze (OR 1.7, 95\% $\mathrm{Cl}=1.5$ to $\left.2.0, I^{2}=37 \%, P=0.134\right)$, and crepitations/crackles (OR 1.7, $95 \% \mathrm{Cl}=1.4$ to $2.2, I^{2}=0 \%, P=0.842$ ) (Figure 3 ). Rales were not significantly associated with RSV IOR $1.2,95 \% \mathrm{Cl}=0.98$ to $1.4, \mathrm{I}^{2}=0 \%$, $P<0.669$ ), and nor was fever (OR 0.97, 95\% $\mathrm{Cl}=0.7$ to $1.3, I^{2}=0 \%, P=0.507$ ). Results

Figure 2. Summary of Appendix 3: evidence for the 1704 potential associations between pathogens and clinical presentation investigated by studies in this review.

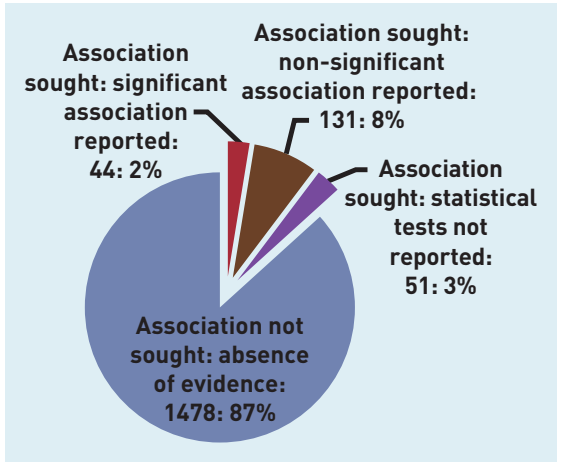




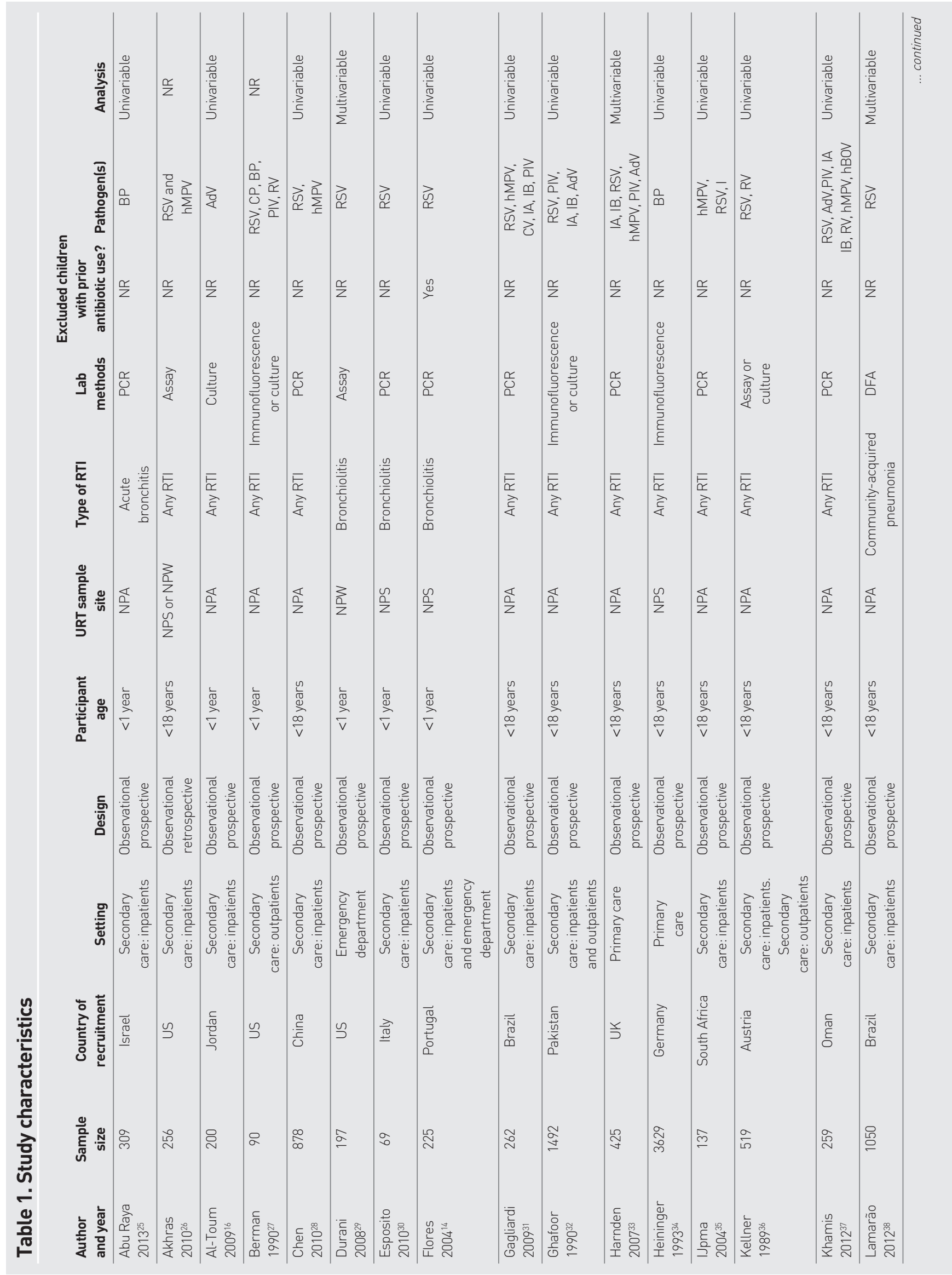




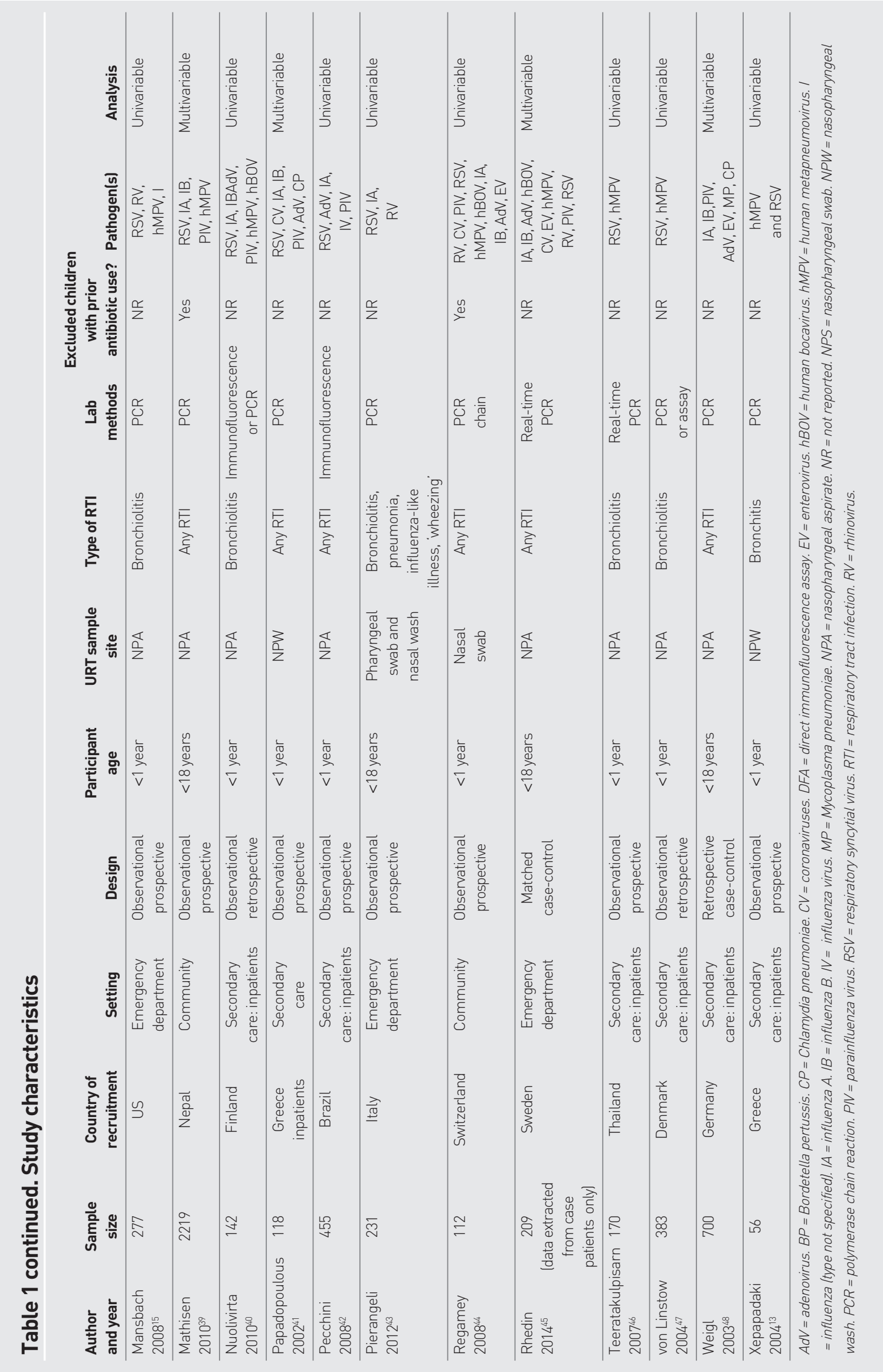




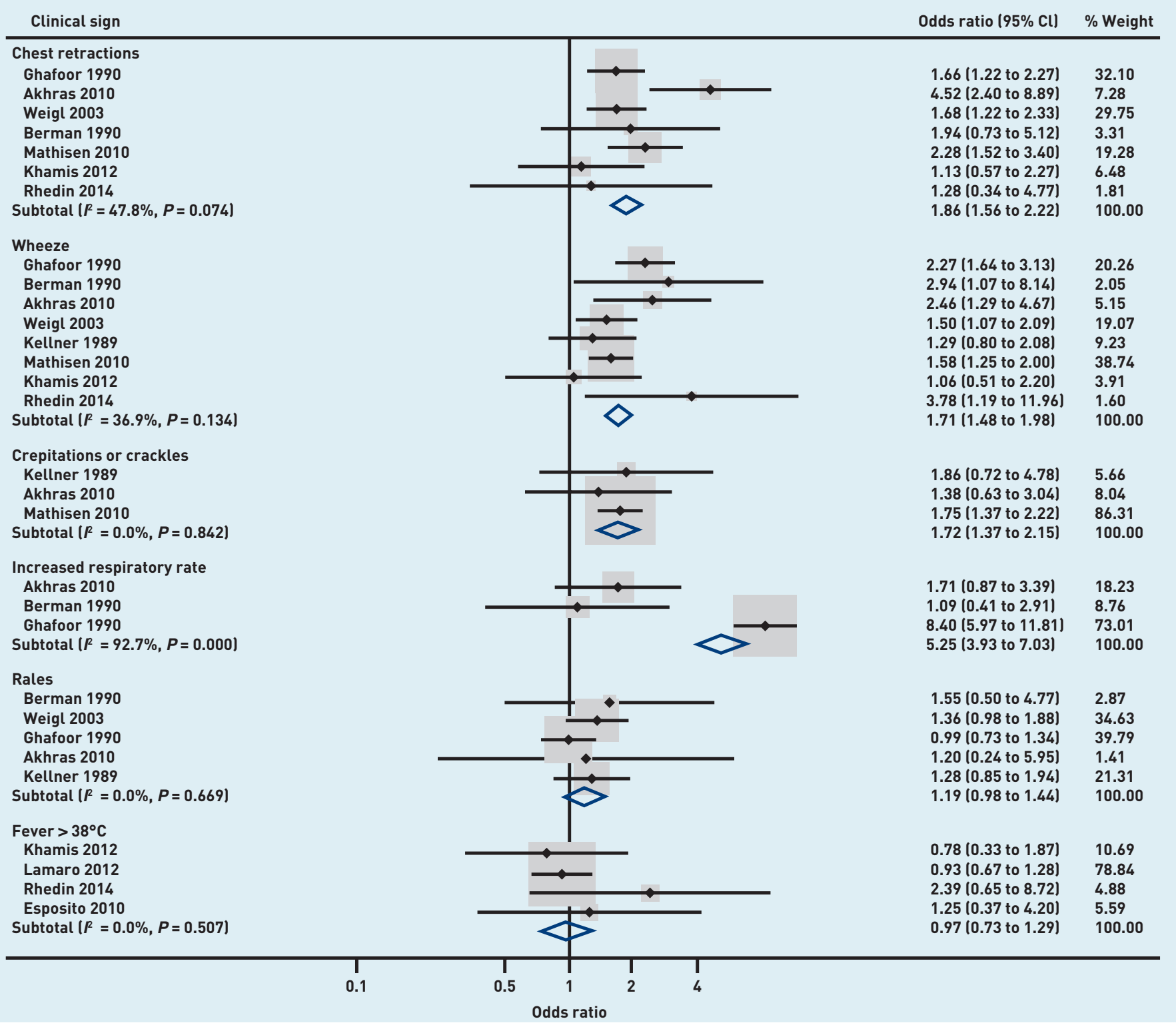

Figure 3. Evidence for the 1704 potential associations between pathogens and clinical presentation investigated by studies in this review. of meta-analysis could not be considered for increased respiratory rate, as the data showed considerable heterogeneity (OR 5.3, $95 \% \mathrm{Cl}=3.9$ to $\left.7.0, /^{2}=93 \%, P<0.001\right)$.

\section{Publication bias}

Publication bias was assessed in the data for wheeze and chest retractions using funnel plots (Appendices 4 and 5). Some evidence of positive publication bias was seen for chest retractions, but there was no evidence of publication bias for wheeze. There were insufficient data to assess publication bias for rales, crepitations/crackles, fever, or increased respiratory rate.

\section{DISCUSSION}

\section{Summary}

There is an absence of evidence evaluating the link between many clinical symptoms or signs and URT respiratory pathogens in children presenting to healthcare services with RTI-associated acute cough. Metaanalysis shows that some clinical signs (chest retractions, wheeze, and crepitations/ crackles) are associated with URT detection of RSV. These results are applicable to children presenting to primary or secondary care with cough. However, caution should be taken in applying them beyond this population due to the effect of age on both URT flora and symptomatic presentation.

\section{Strengths and limitations}

This systematic review and meta-analysis of published literature without language or geographical restrictions was conducted and reported according to the MOOSE 
guidelines. ${ }^{12}$ Included are studies reporting either raw data or statistical results for associations between clinical presentation and URT respiratory pathogen detection, and have presented a unique overview of current knowledge. URT samples were selected for this review as this is the most accessible and acceptable site for primary care microbiological sampling. It is here that future point-of-care tests would most easily sample respiratory tract pathogens.

Reference lists of included articles were hand-searched, but it was beyond the scope of this investigation to search grey literature or conference proceedings.

Absence of multivariable analysis in the published literature means that, while no clear pattern is demonstrable between individual symptoms and signs, important independent associations may have been confounded by the presence of other symptoms and signs. Similarly, studies that failed to test for, or analyse, a broad range of respiratory pathogens may be affected by confounding due to the presence of an untested, or unadjusted for, microbe. Furthermore, the possibility of asymptomatic 'carrier states' was not investigated by these studies.

A lack of consensus was identified regarding the definition of continuous objective signs such as 'hypoxia' and 'fever'. For example, some studies defined 'hypoxaemia' as a blood oxygen saturation level of $<92 \%,{ }^{13-15}$ while in others the cutoff limits were $<95 \% .{ }^{16}$ In the interest of brevity, results for multiple definitions of these signs were combined into a single row in the tables. The use of international guidelines to define such terms in research, or the reporting of raw data, would increase the potential for meaningful comparisons between studies, and quantitative synthesis.

A wide variety of laboratory methods are employed to detect microbes in URT samples, and in many publications little or no validation data or standardisation of methods were described. Further to this, the use of URT samples as the diagnostic reference standard in this review may represent a poor measure of aetiology.

\section{Comparison with existing literature}

Previous work has demonstrated that clinicians use symptoms and signs to inform prescribing decisions in patients with RTI. ${ }^{17}$ Evidence from existing meta-analyses suggests that Mycoplasma pneumoniae and influenza A and B may be associated with symptoms and signs; however, settings were not limited to primary care and reference standards included serological diagnosis. ${ }^{18,19}$ Additionally, a recent study demonstrated that clinical features are moderately diagnostic for the detection of streptococci from the throat in patients presenting to primary care with tonsillitis. ${ }^{20}$

\section{Implications for research and practice}

Clinical guidelines in the UK and Europe advise that prescribing decisions are made based on the severity of disease or potential for complications., 1,21,22 Despite these recommendations, however, previous research has demonstrated that European clinicians use clinical presentation to help them assess the likelihood of bacterial aetiology in their decision making. ${ }^{17,23}$ Overall, given the absence of evidence in this area, clinicians should be cautious about using clinical features to distinguish the 'bacterial' or 'viral' status of RTI in children in primary care. In the absence of a gold-standard aetiological test, further research is needed to establish whether URT microbes are associated with clinical presentation and, more importantly, with prognosis. High-quality, large-scale observational studies investigating a broad panel of respiratory pathogens are lacking. particularly in the primary care setting.

Future research should include other causality metrics in study design, for example, investigating the relationship between microbe quantification and clinical presentation, which could be used to help distinguish microbial aetiology from incidental carriage or asymptomatic infection. Other biomarkers, such as C-reactive protein and procalcitonin, have also been investigated as potential diagnostic aids in $\mathrm{RTI}^{24}$ and their use could be considered in conjunction with URT samples.

This review demonstrates a significant gap in the evidence for using clinical presentation to make a microbiological diagnosis for children presenting with RTI. That said, the meta-analysis shows that clinical presentation is associated with the detection of RSV from the URT. This suggests that clinical presentation could be associated with the detection of other easily accessible URT microbes, which could be used to develop future diagnostic strategies and improve targeting of antimicrobials. 


\section{REFERENCES}

1. National Institute for Health and Care Excellence. Respiratory tract infections prescribing of antibiotics for self-limiting respiratory tract infections in adults and children in primary care. Clinical guideline 69. London: NICE, 2008. http:// publications.nice.org.uk/respiratory-tract-infections-antibiotic-prescribing-cg69 (accessed 26 Nov 2014).

2. Keith T, Saxena S, Murray J, Sharland M. Risk-benefit analysis of restricting antimicrobial prescribing in children: what do we really know? Curr Opin Infect Dis 2010; 23(3): 242-248.

3. Adriaenssens N, Coenen S, Versporten A, et al. European Surveillance of Antimicrobial Consumption (ESAC): outpatient antibiotic use in Europe (19972009). J Antimicrob Chemother 2011; 66(Suppl 6): vi3-vi12.

4. Costelloe $\mathrm{C}$, Metcalfe $\mathrm{C}$, Lovering A, et al. Effect of antibiotic prescribing in primary care on antimicrobial resistance in individual patients: systematic review and meta-analysis. BMJ 2010; DOI: 10.1136/bmj.c2096.

5. Howie JG. Clinical judgement and antibiotic use in general practice. BMJ 1976; 2(6043): 1061-1064.

6. Ashworth M, Charlton J, Ballard K, et al. Variations in antibiotic prescribing and consultation rates for acute respiratory infection in UK practices 1995-2000. Br J Gen Pract 2005; 55(517): 603-608.

7. Ferech M, Coenen S, Malhotra-Kumar S, et al. European Surveillance of Antimicrobial Consumption (ESAC): outpatient antibiotic use in Europe. $J$ Antimicrob Chemother 2006; 58(2): 401-407.

8. Morrell DC. Symptom interpretation in general practice. J R Coll Gen Pract 1972: 22(118): 297-309.

9. Guyatt GH, Oxman AD, Vist G, et al. GRADE guidelines: 4. Rating the quality of evidence - study limitations (risk of bias). J Clin Epidemiol 2011; 64(4): 407-415.

10. Whiting PF, Rutjes AW, Westwood ME, et al. QUADAS-2: a revised tool for the quality assessment of diagnostic accuracy studies. Ann Intern Med 2011; DOI: 10.7326/0003-4819-155-8-201110180-00009.

11. The World Bank. Country and lending groups. http://data.worldbank.org/about/ country-classifications/country-and-lending-groups (accessed 26 Nov 2014).

12. Stroup DF, Berlin JA, Morton SC, et al. Meta-analysis of observational studies in epidemiology: a proposal for reporting. Meta-analysis Of Observational Studies in Epidemiology (MOOSE) group. JAMA 2000; 283(15): 2008-2012.

13. Xepapadaki P, Psarras S, Bossios A, et al. Human Metapneumovirus as a causative agent of acute bronchiolitis in infants. J Clin Virol 2004; 30(3): 267-270.

14. Flores $\mathrm{P}$, Rebelo-De-Andrade $\mathrm{H}$, Goncalves $\mathrm{P}$, et al. Bronchiolitis caused by respiratory syncytial virus in an area of Portugal: epidemiology, clinical features, and risk factors. Eur J Clin Microbiol Infect Dis 2004; 23(1): 39-45.

15. Mansbach JM, McAdam AJ, Clark S, et al. Prospective multicenter study of the viral etiology of bronchiolitis in the emergency department. Acad Emerg Med 2008; 15(2): 111-118.

16. Al-Toum R, Bdour S, Ayyash H. Adenovirus infections in Jordanian hospitalized pediatric patients: prevalence and clinical features. Jordan Med J 2009; 43(3): 5743-5752.

17. Brookes-Howell L, Hood K, Cooper L, et al. Clinical influences on antibiotic prescribing decisions for lower respiratory tract infection: a nine country qualitative study of variation in care. BMJ Open 2012; DOI: 10.1136/bmjopen-2011-000795.

18. Wang K, Gill P, Perera R, et al. Clinical symptoms and signs for the diagnosis of Mycoplasma pneumoniae in children and adolescents with community-acquired pneumonia. Cochrane Database Syst Rev 2012; 10: CD009175.

19. Ebell MH, Afonso A. A systematic review of clinical decision rules for the diagnosis of influenza. [Review]. Ann Fam Med. 2011; 9(1): 69-77.

20. Little P, Moore M, Hobbs FD, et al. PRImary care Streptococcal Management (PRISM) study: identifying clinical variables associated with Lancefield group A $\beta$-haemolytic streptococci and Lancefield non-Group A streptococcal throat infections from two cohorts of patients presenting with an acute sore throat. BMJ Open 2013; DOI: 10.1136/bmjopen-2013-003943.

21. Woodhead M. New guidelines for the management of adult lower respiratory tract infections. Eur Respir J 2011; 38(6): 1250-1251.

22. Verheij ThJM HR, Prins JM, Salomé PhL, et al. NHG-Standaard Acuut hoesten [NHG standard acute cough]. Huisarts Wet 2011; 52(2): 68-92.

23. Cabral C, Ingram J, Hay AD, et al. 'They just say everything's a virus' Parent's judgment of the credibility of clinician communication in primary care consultations for respiratory tract infections in children: a qualitative study. Patient Educ Couns 2014; 95(2): 248-253.

24. Cals JWL, Schot MJC, de Jong SAM, et al. Point-of-care C-reactive protein testing and antibiotic prescribing for respiratory tract infections: a randomized controlled trial. Ann Fam Med 2010; 8(2): 124-133.

25. Abu Raya B, Bamberger E, Kassis I, et al. Bordetella pertussis infection attenuates clinical course of acute bronchiolitis. Pediatr Infect Dis J 2013; 32(6): 619-621.

26. Akhras N, Weinberg JB, Newton D. Human metapneumovirus and respiratory syncytial virus: subtle differences but comparable severity. Infect Dis Rep 2010; DOI: 10.4081/idr.2010.e12.

27. Berman S, Shanks MB, Feiten D, et al. Acute respiratory infections during the first three months of life: clinical, radiologic and physiologic predictors of etiology. Pediatr Emerg Care 1990; 6(3): 179-182

28. Chen $X$, Zhang ZY, Zhao Y, et al. Acute lower respiratory tract infections by human metapneumovirus in children in Southwest China: a 2-year study. Pediatr Pulmonol 2010; 45(8): 824-831.

29. Durani Y, Friedman MJ, Attia MW. Clinical predictors of respiratory syncytial virus infection in children. Pediatr Int 2008; 50(3): 352-355.

30. Esposito $S$, Salice P, Bosis S, et al. Altered cardiac rhythm in infants with bronchiolitis and respiratory syncytial virus infection. BMC Infect Dis 2010; 10: 305.

31. Gagliardi TB, Iwamoto MA, Paula FE, et al. Human bocavirus respiratory infections in children. Epidemiol Infect 2009; 137(7): 1032-1036.

32. Ghafoor A, Nomani NK, Ishaq Z, et al. Diagnoses of acute lower respiratory tract infections in children in Rawalpindi and Islamabad, Pakistan. Rev Infect Dis 1990; 12 (Suppl 8): S907-S914.

33. Harnden A, Perera R, Brueggemann AB, et al. Respiratory infections for which general practitioners consider prescribing an antibiotic: a prospective study. Arch Dis Child 2007; 92(7): 594-597.

34. Heininger U, Cherry JD, Eckhardt T, et al. Clinical and laboratory diagnosis of pertussis in the regions of a large vaccine efficacy trial in Germany. Pediatr Infect Dis J 1993; 12(6): 504-509.

35. IJpma FF, Beekhuis D, Cotton MF, et al. Human metapneumovirus infection in hospital referred South African children. J Med Virol 2004; 73(3): 486-493.

36. Kellner G, Popow-Kraupp T, Kundi M, et al. Clinical manifestations of respiratory tract infections due to respiratory syncytial virus and rhinoviruses in hospitalized children. Acta Paediatr Scand 1989; 78(3): 390-394.

37. Khamis FA, Al-Kobaisi MF, Al-Areimi WS, et al. Epidemiology of respiratory virus infections among infants and young children admitted to hospital in Oman. J Med Virol 2012; 84(8): 1323-1329

38. Lamarão LM, Ramos FL, Mello WA, et al. Prevalence and clinical features of respiratory syncytial virus in children hospitalized for community-acquired pneumonia in northern Brazil. BMC Infect Dis 2012; 12: 119.

39. Mathisen M, Strand TA, Sharma BN, et al. Clinical presentation and severity of viral community-acquired pneumonia in young Nepalese children. Pediatr Infect Dis J 2010; DOI: 10.1097/INF.0b013e3181c2a1b9.

40. Nuolivirta K, Koponen $\mathrm{P}, \mathrm{He}$ Q, et al. Bordetella pertussis infection is common in nonvaccinated infants admitted for bronchiolitis. Pediatr Infect Dis J 2010; 29(11): 1013-1015.

41. Papadopoulos NG, Moustaki M, Tsolia M, et al. Association of rhinovirus infection with increased disease severity in acute bronchiolitis. Am J Respir Crit Care Med 2002; 165(9): 1285-1289.

42. Pecchini R, Berezin EN, Felicio MCC, et al. Incidence and clinical characteristics of the infection by the respiratory syncytial virus in children admitted in Santa Casa de São Paulo Hospital. Braz J Infect Dis 2008; 12(6): 476-479

43. Pierangeli A, Scagnolari C, Selvaggi C, et al. Virological and clinical characterization of respiratory infections in children attending an emergency department during the first autumn-winter circulation of pandemic A (H1N1) 2009 influenza virus. Clin Microbiol Infect 2012; 18(4): 366-373

44. Regamey N, Kaiser L, Roiha HL, et al. Viral etiology of acute respiratory infections with cough in infancy: a community-based birth cohort study. Pediatr Infect Dis $J$ 2008; 27(2): 100-105.

45. Rhedin S, Lindstrand A, Rotzén-Östlund M, et al. Clinical utility of PCR for common viruses in acute respiratory illness. Pediatrics 2014; DOI: 10.1542/ peds.2013-3042.

46. Teeratakulpisarn J, Ekalaksananan T, Pientong C, Limwattananon C. Human metapneumovirus and respiratory syncytial virus detection in young children with acute bronchiolitis. Asian Pac J Allergy Immunol 2007; 25(2-3): 139-145.

47. von Linstow ML, Larsen HH, Eugen-Olsen J, et al. Human metapneumovirus and respiratory syncytial virus in hospitalized Danish children with acute respiratory tract infection. Scand J Infect Dis 2004; 36(8): 578-584.

48. Weigl JA, Puppe W, Schmitt HJ. Can respiratory syncytial virus etiology be diagnosed clinically? A hospital-based case-control study in children under two years of age. Eur J Epidemiol 2003; 18(5): 431-439. 


\section{Appendix 1. MEDLINE search strategy}

characteristic*.tw.

manifest*.tw.

symptom*.tw.

cough*.tw.

headache.tw.

"Chest pain".tw

Breathlessness.tw

"runny nose".tw.

"Chest tightness".tw

clinical sign*.tw

fever.tw.

temperature.tw.

"head bobbing".tw

Cyanosis.tw

"pursed lip*".tw

"nasal flaring".tw.

coryza*.tw

stridor.tw.

mucus.tw

sputum.tw

dyspnoea.tw

"Short* of breath".tw

"intercostal recession".tw.

tachypnoea.tw

hyperpnoea.tw

wheez*.tw.

crepitation*.tw.

"pleural rub".tw

"bronchial breathing”.tw

crackles.tw

ronchi.tw

"vocal resonance".tw

fremitus.tw

"peak flow".tw

"oxygen saturation".tw

sats.tw

1 or 2 or 3 or 4 or 5 or 6 or 7 or 8 or 9 or 10 or 11 or 12 or 13 or 14 or 15 or 16 or 17 or 18 or 19 or 20 or 21 or 22 or 23 or 24 or

25 or 26 or 27 or 28 or 29 or 30 or 31 or 32 or 33 or 34 or 35 or 36 diagnos*.tw.

role.tw.

cause.tw.

effect.tw.

significance.tw.

importance.tw.

predict*.tw

rule.tw

manifest*.tw

judgement.tw

judgment.tw

38 or 39 or 40 or 41 or 42 or 43 or 44 or 45 or 46 or 47 or 48

bacterial infections/

"chlamydia pneumonia*".tw.

"chlamydophila pneumonia*".tw.

"c pneumonia*".tw. "mycoplasma pneumonia*".tw.

"m pneumonia".tw.

"bordetella parapertussis".tw.

"b parapertussis".tw.

"bordetella pertussis".tw.

"b pertussis".tw.

"staphylococcus aureus".tw.

"staph aureus".tw.

"s aureus".tw.

beta haemolytic streptococc*.tw.

"beta hemolytic streptococc*".tw.

"moraxella catarrhalis".tw.

"m catarrhalis".tw.

"influenza*".tw.

"streptococcus pneumonia*".tw.

"strep pneumonia*".tw.

"s pneumonia*".tw.

virus diseases/

rsv.tw.

"respiratory syncytial virus".tw.

parainfluenzavirus.tw.

metapneumovirus.tw.

adenovirus.tw.

coronavirus.tw.

rhinovirus.tw.

enterovirus.tw.

parechovirus.tw.

bocavirus.tw.

50 or 51 or 52 or 53 or 54 or 55 or 56 or 57 or 58 or 59 or 60 or 61 or 62 or 63 or 64 or 65 or 66 or 67 or 68 or 69 or 70 or 71 or 72 or 73 or 74 or 75 or 76 or 77 or 78 or 79 or 80 or 81

croup.tw.

respiratory tract infection/

bronchitis.tw.

common cold/

cough.tw.

bronchiolitis.tw.

sinusitis.tw

rhinitis.tw

pertussis.tw

"whooping cough".tw38 diagnos*.tw.

pneumonia.tw

flu.tw

Influenza.tw

tracheitis.tw

empyema.tw

broncopneumonia.tw

83 or 84 or 85 or 86 or 87 or 88 or 89 or 90 or 01 or 02 or

93 or 94 or 95 or 96 or 97 or 98

100

37 and 49 and 82 and 99

101 limit 100 to (English language and humans and all child [0 to 17 years]) 
Appendix 2. Quality assessment

\begin{tabular}{|c|c|c|c|c|c|c|c|c|c|c|c|}
\hline Author & 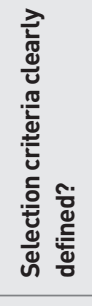 & 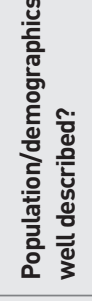 & 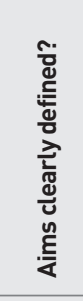 & 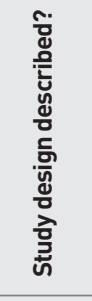 & 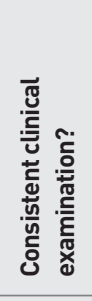 & 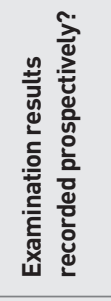 & 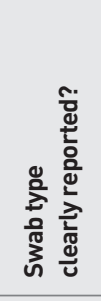 & 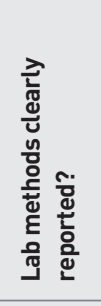 & 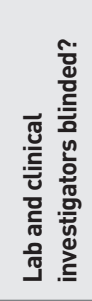 & 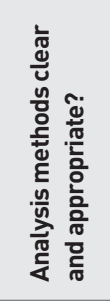 & 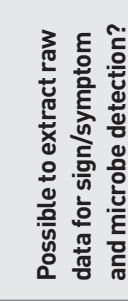 \\
\hline Abu Raya 2013 & $\varnothing$ & $\theta$ & 0 & $\theta$ & $\theta$ & $\theta$ & $\theta$ & 0 & $\boldsymbol{x}$ & $\theta$ & 0 \\
\hline Akhras 2010 & $\boldsymbol{x}$ & $\Theta$ & 0 & 0 & $\Theta$ & $\theta$ & $\boldsymbol{\otimes}$ & 0 & $\theta$ & $\theta$ & 0 \\
\hline Al-Toum 2009 & $\theta$ & $\Theta$ & 0 & $\theta$ & $\Theta$ & $\boldsymbol{x}$ & $\Theta$ & 0 & $\Theta$ & $\theta$ & 0 \\
\hline Berman 1990 & $\Theta$ & $\Theta$ & 0 & $\Theta$ & $\theta$ & $\theta$ & $\theta$ & $\theta$ & $\Theta$ & $\Theta$ & $\theta$ \\
\hline Chen 2010 & $\theta$ & $\theta$ & $\theta$ & $\varnothing$ & $\Theta$ & $\boldsymbol{x}$ & 0 & 0 & $\theta$ & $\theta$ & $\boldsymbol{\otimes}$ \\
\hline Durani 2008 & $\theta$ & $\theta$ & 0 & 0 & $\theta$ & $\theta$ & $\Theta$ & 0 & $\Theta$ & 0 & $\boldsymbol{\otimes}$ \\
\hline Esposito 2010 & $\theta$ & $\theta$ & 0 & $\theta$ & $\theta$ & $\theta$ & $\theta$ & 0 & $\Theta$ & 0 & 0 \\
\hline Flores 2004 & $\theta$ & $\theta$ & 0 & $\theta$ & $\theta$ & $\theta$ & $\theta$ & 0 & $\theta$ & $\theta$ & 0 \\
\hline Gagliardi 2009 & $\theta$ & $\Theta$ & $\theta$ & $\varnothing$ & $\Theta$ & $\Theta$ & 0 & 0 & $\Theta$ & $\theta$ & $\boldsymbol{\otimes}$ \\
\hline Ghafoor 1990 & $\Theta$ & $\boldsymbol{x}$ & $\Theta$ & - & $\theta$ & $\theta$ & $\Theta$ & 0 & $\theta$ & 0 & $\theta$ \\
\hline Harnden 2007 & $\theta$ & $\theta$ & 0 & $\varnothing$ & $\theta$ & $\theta$ & $\theta$ & 0 & $\theta$ & 0 & $\boldsymbol{\otimes}$ \\
\hline Heiniger 1993 & $\theta$ & $\theta$ & 0 & $\theta$ & $\Theta$ & $\theta$ & $\theta$ & 0 & $\Theta$ & $\theta$ & $\theta$ \\
\hline IJpma 2004 & $\theta$ & $\varnothing$ & 0 & 0 & $\Theta$ & $\Theta$ & $\theta$ & 0 & $\Theta$ & 0 & $\boldsymbol{x}$ \\
\hline Kellner 1989 & $\theta$ & $\boldsymbol{x}$ & 0 & $\Theta$ & $\Theta$ & $\boldsymbol{x}$ & 0 & 0 & $\Theta$ & 0 & 0 \\
\hline Khamis 2012 & $\Theta$ & $\theta$ & 0 & $\varnothing$ & $\Theta$ & $\theta$ & 0 & 0 & $\boldsymbol{x}$ & $\theta$ & 0 \\
\hline Lamarão 2012 & $\theta$ & $\boldsymbol{x}$ & $\Theta$ & $\Theta$ & $\theta$ & $\theta$ & $\theta$ & $\theta$ & $\theta$ & $\theta$ & 0 \\
\hline Mansbach 2008 & $\theta$ & $\varnothing$ & $\theta$ & $\varnothing$ & 0 & $\boldsymbol{x}$ & 0 & 0 & $\Theta$ & $\theta$ & 0 \\
\hline Mathisen 2010 & $\theta$ & $\theta$ & 0 & $\Theta$ & $\theta$ & $\theta$ & $\theta$ & 0 & $\Theta$ & 0 & $\theta$ \\
\hline Nuolivirta 2010 & $\Theta$ & $\varnothing$ & 0 & $\varnothing$ & $\theta$ & $\boldsymbol{x}$ & $\Theta$ & $\Theta$ & $\theta$ & $\theta$ & 0 \\
\hline Papadopoulos 2002 & $\theta$ & $\theta$ & 0 & $\theta$ & $\theta$ & $\theta$ & $\theta$ & 0 & $\theta$ & $\theta$ & $\boldsymbol{\otimes}$ \\
\hline Pecchini 2008 & $\theta$ & $\theta$ & 0 & ○ & $\theta$ & $\theta$ & 0 & $\theta$ & $\Theta$ & $\theta$ & 0 \\
\hline Pierangeli 2012 & $\theta$ & $\boldsymbol{x}$ & 0 & 0 & $\theta$ & $\theta$ & $\theta$ & 0 & $\boldsymbol{x}$ & 0 & $\boldsymbol{\otimes}$ \\
\hline Regamey 2008 & $\theta$ & $\boldsymbol{x}$ & 0 & $\theta$ & $\theta$ & $\theta$ & $\theta$ & 0 & $\Theta$ & 0 & 0 \\
\hline Rhedin 2014 & $\theta$ & $\theta$ & 0 & $\theta$ & $\theta$ & $\theta$ & $\Theta$ & $\ominus$ & $\boldsymbol{x}$ & $\theta$ & $\theta$ \\
\hline Teeratalkulpisarn 2007 & $\Theta$ & $\theta$ & $\theta$ & $\Theta$ & $\Theta$ & $\Theta$ & 0 & $\theta$ & $\Theta$ & $\theta$ & $\boldsymbol{\otimes}$ \\
\hline von Linstow 2014 & $\Theta$ & $\theta$ & 0 & $\Theta$ & $\boldsymbol{x}$ & $\boldsymbol{x}$ & $\theta$ & $\Theta$ & $\theta$ & $\theta$ & $\boldsymbol{\otimes}$ \\
\hline Weigl 2003 & $\varnothing$ & $\boldsymbol{x}$ & 0 & $\varnothing$ & $\varnothing$ & $\theta$ & $\theta$ & $\Theta$ & $\varnothing$ & $\varnothing$ & 0 \\
\hline Xepapadaki 2004 & 0 & 0 & 0 & $\Theta$ & $\Theta$ & 0 & 0 & 0 & $\Theta$ & 0 & $\boldsymbol{\otimes}$ \\
\hline
\end{tabular}




\begin{tabular}{|c|c|c|c|c|c|c|c|c|c|c|c|c|c|c|}
\hline & $\begin{array}{l}\text { iptom } \\
\text { ign (bold text) }\end{array}$ & के & $\sum_{i=1}^{a}$ & 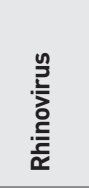 & 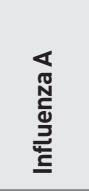 & 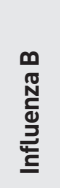 & 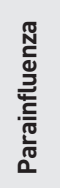 & 峞 & 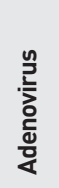 & 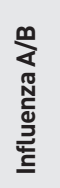 & 总 & 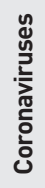 & 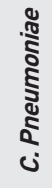 & \\
\hline & Rhinitis & (2) & (2) & (1) & (1) & (1) & 2 & 0 & (1) & 0 & 0 & (1) & 0 & \\
\hline & Rhinorrhoea (symptom) & (1) (4) (1) & (1)(1) & o & (1) & (1) & 0 & 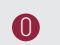 & 0 & (1) & 0 & D & & \\
\hline & Congestion & (2) 1 & (1) & 0 & 0 & $\mathbf{0}$ & 0 & 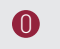 & 0 & 0 & 0 & 0 & 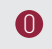 & \\
\hline$\vec{\pi}$ & 'Runny nose, nasal obstruction or sneezes' & (1) & 0 & o & 0 & $\mathbf{0}$ & 0 & 0 & 0 & 0 & 0 & 0 & 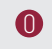 & \\
\hline$\stackrel{\frac{\pi}{2}}{\lambda}$ & Sneezing & 0 & 0 & 0 & 0 & $\mathbf{0}$ & 0 & 0 & 0 & 0 & (1) & 0 & U & \\
\hline$\frac{5}{0}$ & Nasal flare & (1) & 0 & (1) & 0 & 0 & 0 & 0 & 0 & 0 & 0 & 0 & 0 & \\
\hline$\frac{\bar{c}}{\bar{y}}$ & Coryza & 0 & 0 & 0 & 0 & 0 & 0 & (0) & 0 & 0 & (1) & 0 & 0 & \\
\hline 递 & Rhinorrhoea (sign) & (1) 1 & (1) & (0) & 0 & 0 & 0 & 0 & 0 & 0 & 0 & 0 & 0 & \\
\hline$\frac{0}{2}$ & Inspiratory stridor & (1) & 0 & 0 & 0 & 0 & 0 & (0) & 0 & 0 & 0 & 0 & 0 & \\
\hline & Stridor & (1) & 0 & 0 & 0 & $\mathbf{0}$ & 0 & 0 & 0 & 0 & 0 & 0 & 0 & \\
\hline & Expiratory stridor & (1) & 0 & (1) & 0 & (0) & 0 & 0 & 0 & 0 & 0 & 0 & 0 & \\
\hline & Cough reported by parent & (2) (1) & (1) (1) & (1) & (1) & (1) & 0 & (1) & 0 & (1) & (1) & 0 & $\mathbf{0}$ & \\
\hline 홍 & Post-tussive vomiting & 0 & 0 & 0 & 0 & 0 & 0 & (1) & 0 & 0 & 0 & 0 & 0 & \\
\hline ö & Paroxysmal cough & 0 & 0 & (0) & 0 & 0 & 0 & (1) & 0 & 0 & 0 & 0 & 0 & \\
\hline & Cough & (3) 2 & (1) & (1) & (1) & 0 & 0 & (1) & 0 & 0 & 0 & 0 & 0 & \\
\hline & Tight chest & (1) & (1) & 0 & (1) & (1) & 0 & 0 & 0 & 0 & 0 & 0 & 0 & \\
\hline & Wheezing history & (2) & (1) & (1) & 0 & (0) & (1) & 0 & 0 & 0 & 0 & (1) & 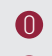 & \\
\hline & Rapid breathing reported & (1) & (1) & 0 & 0 & 0 & 0 & 0 & 0 & 0 & 0 & 0 & ) & \\
\hline & Difficulty breathing (maternal report) & (1) & (1) & (0) & 0 & 0 & 0 & (0) & 0 & 0 & 0 & 0 & 0 & \\
\hline & Apnoea (symptom) & (1) 1 & (1) & 0 & 0 & 0 & 0 & 0 & 0 & 0 & 0 & 0 & 0 & \\
\hline & Grunting & (1) (1) & 0 & 0 & 0 & 0 & 0 & 0 & 0 & 0 & 0 & 0 & 0 & \\
\hline & Tracheal aspirate & (1) & 0 & (1) & 0 & 0 & 0 & 0 & 0 & 0 & 0 & 0 & 0 & \\
\hline & Chest retraction/indrawing & (4) 2 & (1) (1) & (1) & (1) & (1) & (1) & 0 & (1) & 0 & 0 & 0 & 0 & \\
\hline & Hyperinflation & (1) & (1) & 0 & 0 & 0 & 0 & 0 & 0 & 0 & 0 & 0 & 0 & \\
\hline$\stackrel{\frac{\pi}{2}}{\longrightarrow}$ & Crepitations or crackles & $22(2)$ & (1) 2(1) & (1) 1 & (3) & (1) & (1) & (1) & (1) & 0 & 0 & 0 & 0 & \\
\hline$\frac{\substack{0 \\
\frac{0}{0}}}{0}$ & Wheeze & (4) 2 & (1) 3 & (2) & (1) 3 & (3) & (2) & (1) & (1) & 0 & 0 & 0 & 0 & \\
\hline 哭 & Ronchi & (1) (1) & (1) (1) & 0 & 0 & 0 & 0 & 0 & 0 & 0 & 0 & 0 & 0 & \\
\hline 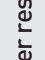 & Rales & (3) 2 & (1) & (1) & 0 & 0 & 0 & 0 & 0 & 0 & 0 & 0 & 0 & \\
\hline 密 & Reduced breath sounds & (1) 2 & (1) & 0 & 0 & 0 & 0 & (1) & 0 & 0 & 0 & 0 & 0 & \\
\hline & Intensified breath sounds & (1) & 0 & (1) & 0 & 0 & 0 & 0 & 0 & 0 & 0 & 0 & 0 & \\
\hline & 'Increased' respiratory rate & (26) & (1) (1) & (1) & 0 & 0 & 0 & (1) & (1) & 0 & 0 & 0 & 0 & \\
\hline & Mean breath frequency & (2) & (1) & (0) & (1) & (1) & 0 & 0 & 0 & 0 & 0 & 0 & 0 & \\
\hline & Dyspnoea & (1) & 0 & (0) & 0 & 0 & 0 & 0 & 0 & 0 & (1) & 0 & 0 & \\
\hline & Respiratory distress & (1) & (1) & (0) & 0 & 0 & 0 & 0 & 0 & 0 & 0 & 0 & 0 & \\
\hline & Respiratory failure & (2) & (1) & 0 & 0 & (0) & 0 & 0 & 0 & 0 & 0 & 0 & 0 & \\
\hline & Hypoxia $<92 \%$ or $<95 \%$ & (24) & (3) & 2 & (2) & 2 & (1) & (1) & (1) & (0) & 0 & (2) & 0 & \\
\hline & Apnoea (not defined as symptom/sign) & (0) & 0 & (0) & 0 & 0 & 0 & 0 & 0 & 0 & (1) & 0 & 0 & \\
\hline & Prolonged expirium & (1) & 0 & (1) & 0 & 0 & 0 & 0 & 0 & (1) & 0 & 0 & 0 & \\
\hline & Headache & 0 & 0 & 0 & (1) & (1) & 0 & 0 & 0 & (1) & 0 & 0 & 0 & \\
\hline & Earache & (1) 1 & (1) & 0 & 0 & 0 & 0 & 0 & 0 & 0 & 0 & 0 & 0 & \\
\hline $\bar{\Phi}$ & Conjunctivitis (symptom) & (1) & (1) & 0 & (1) & (1) & (1) & 0 & (1) & 0 & 0 & 0 & 0 & \\
\hline ] & Watery eyes & (1) & (1) & 0 & 0 & 0 & 0 & 0 & 0 & 0 & 0 & 0 & 0 & \\
\hline$\stackrel{\mathbb{\Xi}}{\underline{\Psi}}$ & Red eyes & (1) & (1) & (1) & 0 & 0 & 0 & 0 & 0 & 0 & 0 & 0 & 0 & \\
\hline
\end{tabular}




\begin{tabular}{|c|c|c|c|c|c|c|c|c|c|c|c|c|c|c|}
\hline & $\begin{array}{l}\text { ptom (cells not shaded) } \\
\text { gn (cells shaded) }\end{array}$ & 茨 & $\sum_{\underline{1}}^{\frac{a}{2}}$ & 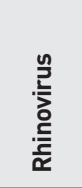 & 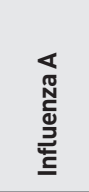 & 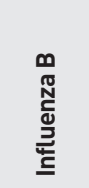 & 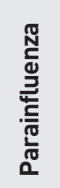 & 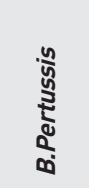 & 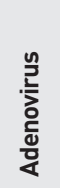 & 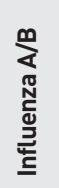 & 总 & 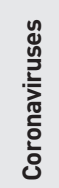 & 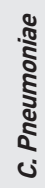 & $\begin{array}{l}\text { हैं } \\
\text { हूँ } \\
\Sigma \\
\Sigma\end{array}$ \\
\hline & Red eyes & (1) & (1) & 0 & 0 & 0 & 0 & 0 & 0 & 0 & 0 & 0 & 0 & 0 \\
\hline & Sore throat & (1) 1 & (1) & 0 & 0 & 0 & 0 & 0 & 0 & (1) & 0 & 0 & 0 & \\
\hline 离 & Signs of otitis media & (2) & (1) & 0 & 0 & 0 & 0 & 0 & 0 & 0 & 0 & 0 & 0 & \\
\hline$\stackrel{\infty}{\infty}$ & Conjunctivitis (sign) & (1) 1 & (1) & 0 & 0 & 0 & 0 & 0 & 0 & 0 & 0 & 0 & 0 & \\
\hline & Red throat & (1) & 0 & (1) & 0 & 0 & 0 & 0 & 0 & 0 & 0 & 0 & 0 & \\
\hline & Swollen occipital/cervical glands & (1) 2 & (1) & (1) & 0 & 0 & 0 & 0 & 0 & 0 & 0 & 0 & 0 & \\
\hline 己 & Increased heart rate & $22(1)$ & (1) 1 & (1) & 0 & 0 & 0 & (1) & 0 & 0 & 0 & 0 & 0 & \\
\hline ๘ & Vomiting & (1) & (1) & 0 & 0 & 0 & (0) & 0 & (0) & 0 & 0 & 0 & 0 & \\
\hline 喜 & Abdominal pain & 0 & 0 & 0 & 0 & 0 & 0 & 0 & 0 & (1) & 0 & 0 & 0 & \\
\hline 苋 & Diarrhoea & (1) & (1) & 0 & 0 & o & 0 & o & 0 & (1) & 0 & 0 & 0 & \\
\hline 忘 & Difficulty feeding & (1) & (1) & 0 & 0 & 0 & 0 & 0 & 0 & 0 & 0 & 0 & 0 & \\
\hline & 'Gastrointestinal symptoms' & (1) 2 & (1) & 0 & 0 & 0 & 0 & 0 & 0 & 0 & 0 & 0 & 0 & \\
\hline & Activity disruption & (1) & (1) & (1) & 0 & 0 & (1) & 0 & 0 & 0 & 0 & (1) & 0 & \\
\hline & Reported severity/overall symptom score & (1) & (1) & (1) & 0 & 0 & (1) & 0 & 0 & 0 & 0 & (1) & 0 & \\
\hline & Reported fever & 0 & (2) & (1) & 0 & 0 & (1) & (1) & (1) & 0 & 0 & (1) & 0 & \\
\hline & Fatigue & (1) & (1) & 0 & 0 & 0 & 0 & 0 & (0) & 0 & 0 & 0 & 0 & \\
\hline & Rash & (1) & (1) & 0 & 0 & o & 0 & o & 0 & 0 & 0 & 0 & 0 & \\
\hline & Myalgia & 0 & 0 & 0 & 0 & 0 & 0 & 0 & 0 & (1) & 0 & 0 & 0 & \\
\hline & Decreased urine output & (1) & (1) & 0 & 0 & 0 & 0 & 0 & 0 & 0 & 0 & 0 & 0 & \\
\hline & Duration of symptoms prior to presentation & (2) & (1) & (1) & 0 & 0 & 0 & 0 & 0 & 0 & 0 & 0 & 0 & \\
\hline 离 & Overall duration of symptoms & (1) & (1) & (1) & (1) & (1) & (1) & (1) & 0 & 0 & 0 & 0 & 0 & \\
\hline & Fever $37.5^{\circ} \mathrm{C}$ & (4) & (3) & (1) & 0 & 0 & 0 & 0 & 0 & 0 & 0 & 0 & 0 & \\
\hline & Fever $>38^{\circ} \mathrm{C}$ & (1) (4) & 2 & (1) & 22 & (1) & (1) & 12 & 0 & 0 & 0 & 0 & 0 & \\
\hline & Fever (threshold not defined) & $(4)$ & 0 & (1) & 0 & 0 & 0 & 0 & 0 & 0 & 0 & 0 & 0 & \\
\hline & Cyanosis & (3) & (1) & 0 & 0 & (0) & 0 & (0) & 0 & 0 & 0 & 0 & 0 & \\
\hline & Poor perfusion & (1) & (1) & & 0 & 0 & 0 & 0 & 0 & 0 & 0 & 0 & 0 & \\
\hline & Clinically assessed severity/severity score & 23 & (2) & (2) & (1) & (1) & (2) & (1) & (2) & 0 & (1) & 2 & (1) & \\
\hline & Acute symptom onset & (1) & 0 & 0 & 0 & 0 & 0 & 0 & 0 & 0 & 0 & 0 & 0 & \\
\hline & Length of stay & (2) & $(10)$ & 0 & (0) & 0 & 0 & 0 & 0 & 0 & 0 & 0 & 0 & \\
\hline
\end{tabular}

The numbers in each cell indicate the number of studies in this review which investigated each potential association between a symptom (left hand column, standard text) or sign (bold text) and a microbe Itop row). Brown circles / / represent studies reporting statistically significant associations. Blue circles (O/ represent studies reporting nonstatistically significant associations. Yellow circles $1 \bigcirc$ indicate studies in which raw data was presented, but no statistical analysis was performed. Red circles $/ O$ indicate that no data were found for the relationship. 


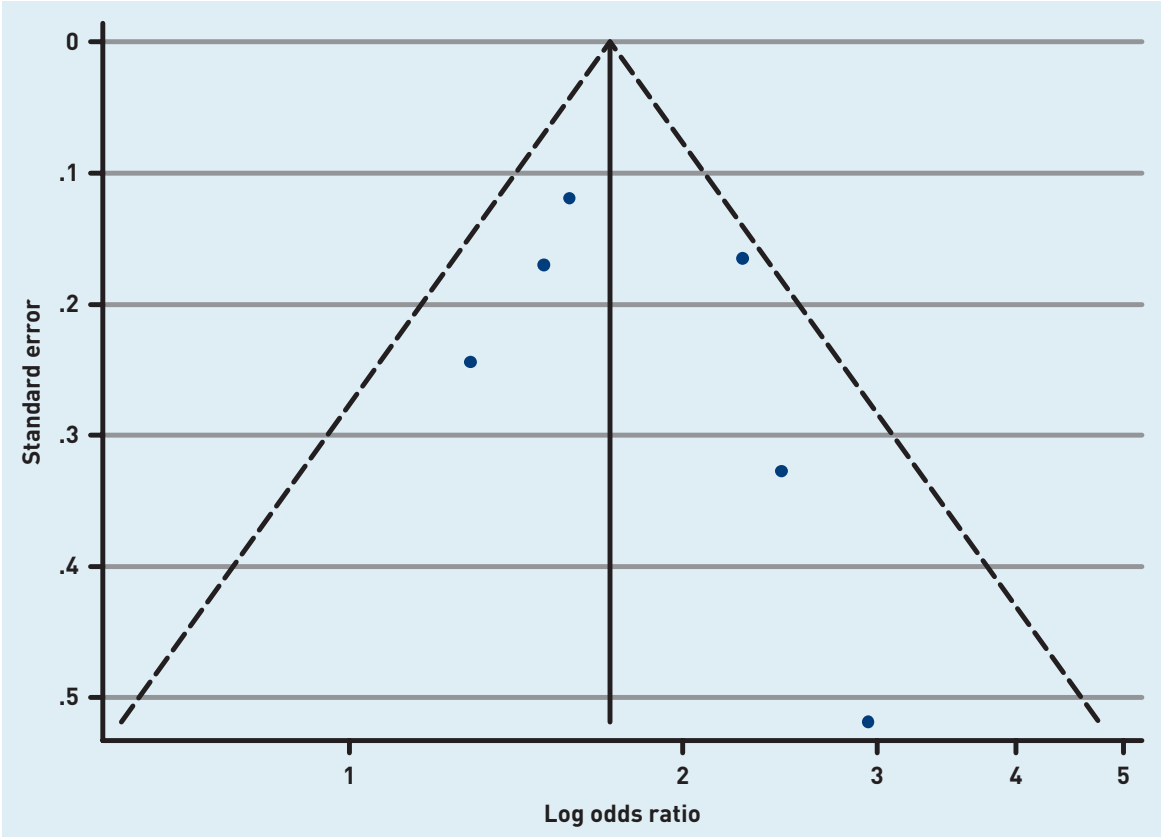

Appendix 4. Funnel plot with pseudo 95\% Cls for studies reporting the relationship between wheeze and respiratory syncytial virus detection.

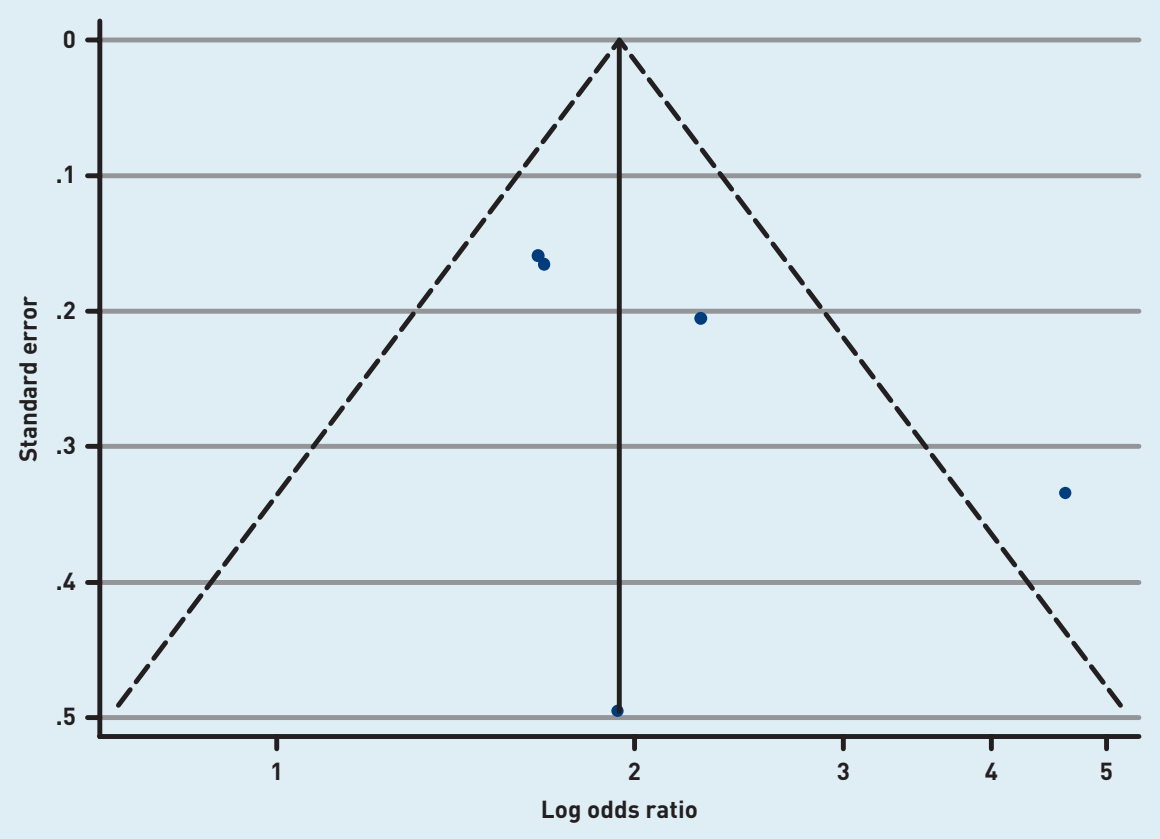

Appendix 5. Funnel plot with pseudo 95\% Cls for studies reporting the relationship between chest retractions and respiratory syncytial virus detection. 